\title{
Age estimation with cemental incremental lines in normal and periodontally diseased teeth using phase contrast microscope: an original research
}

\author{
Ameena Sultana ${ }^{1 *}\left(\mathbb{0}\right.$, Heena Zainab', Pramod Jahagirdar², Deepa Hugar ${ }^{1}$ and Shaimaa ${ }^{3}$
}

\begin{abstract}
Background: Age estimation is an important factor in forensic science for human identification. Teeth are considered to play a vital role as they resist decomposition at death unlike other tissues. This resistance and the gradual structural changes that take place throughout the life of an individual have made teeth useful indicators for age estimation. Dental cementum shows continuous apposition throughout the life of an individual. Tooth cemental annulation is a microscopic method for the determination of an individual's age based on the analysis of incremental lines of cementum. Light microscopy as well as specialized microscopic methods have been employed to enhance the assessment of the cemental annulations. Periodontal disease is the most common dental problem affecting millions of people. Assessing the efficiency of the tooth cemental annulations method in periodontally diseased teeth is an important requisite. This study aims at assessing and evaluating the tooth cemental annulations in normal and periodontally diseased teeth using phase contrast microscopic method for age determination.
\end{abstract}

Results: A total of 60 teeth were included in the study and out of which 30 teeth were normal (sound teeth without any associated pathologies) and 30 were periodontally involved teeth respectively. Longitudinal ground sections were prepared and observed under phase contrast microscope. Measurements were made using an image analyzer software. The total width of the cementum was divided by the distance between two incremental lines. The eruption age of the tooth was then added to this to obtain the chronologic age for each individual. The results in the present study showed that tooth cemental annulations are applicable to periodontally sound teeth as well as in periodontally diseased teeth. There was no significant difference of estimated age from the actual age in both periodontally sound and periodontally diseased teeth. Normal teeth showed a reliability value of $92 \%$ and periodontally compromised teeth showed $96 \%$ respectively. There was no substantial influence of periodontal health on the estimated age.

Conclusions: The study concludes that the use of phase contrast microscopy in conjunction with image enhancement procedures improves the accuracy of age estimation and may serve as a reliable aid in forensic identification.

Keywords: Age estimation, Cementum, Forensic odontology, Microscope

\footnotetext{
${ }^{*}$ Correspondence: mrsabdulmajid@gmail.com

1 Department of Oral Pathology and Microbiology, Al Badar Dental

College and Hospital, Kalaburagi, Karnataka 585102, India

Full list of author information is available at the end of the article
}

\section{Background}

Human identity is the hallmark of civilization, and the identification of unknown individuals always has been of great importance to the society. In this modern speedy epoch, several incidents are taking place, varying from natural calamities to unwanted disasters. Forensic 
Odontology is considered as reliable and trustworthy for the identification of the victims of such disasters (Irish and Scott 2016). In the oro-facial region, the tooth serves as the best source in forensic science. The teeth are one of the hard tissues which undergo the least amount of degenerative changes when exposed to environmental factors (Schemeling et al. 2016).

Age estimation plays a vital role in the recognition of an individual (Gowda Charan et al. 2014). Teeth undergo structural changes throughout life; these changes form the core essence for age estimation. Cementum is a hard tissue of the tooth root which is deposited regularly throughout the life of an individual, even when individual growth is completed (Meinl et al. 2008). This regular deposition of cementum occurs in a rhythmic pattern ensuing the appearance of dark and light bands. One pair of dark and light band represents one increment, which is deposited annually (Kagerer and Grupe 2001). The counting of cemental annulations, i.e., the tooth cementum annulation (TCA) method, was applicable to historical skeletons and cremations to assess the age at death and has now been extended to forensic cases.

Counting cemental annulations requires histological examination of thin tooth sections. Technical improvements and new technologies to help differentiate the lines have been proposed (Dias et al. 2010), but decreased accuracy of the technique in more advanced ages and the influence of periodontal diseases are still factors that require better understanding.

Few studies have applied the TCA method on periodontally affected teeth and demonstrated varying results. Therefore, the purpose of this study was to evaluate the correlation between the number of incremental lines in cementum and the age of the individual with the aid of phase contrast microscope and, also, to analyze the influence of periodontal health on the age estimates.

\section{Methods}

The present study was a prospective study, carried out in the Department of Oral Pathology and Microbiology which was conducted over a period of 6 months. The study was conducted on extracted teeth from individuals of age ranging from 20 to 50 years. Extracted teeth were obtained from the Department of Oral and Maxillofacial Surgery and convenience sampling was adopted. The study samples comprised of a total of 60 teeth, of which 30 were sound teeth and the remaining 30 were periodontally diseased teeth, respectively.

The sample of the study was calculated using the formula:

$Z_{1-\alpha / 2}=$ Standard normal variate (at $5 \%$ type 1 error $(p<0.05)$ it is 1.96).
$\mathrm{SD}=$ Standard deviation of the variable.

$d=$ permissive error of mean.

For the present study, the following values were taken to attain the sample size:

$Z_{1-\alpha / 2}=1.96$ at $5 \%$ type 1 error $(p<0.05)$.

$\mathrm{SD}=3.3$ (difference of means taken from the previously done study by Aggarwal et al. (Aggarwal et al. 2008)).

$d=5 \%$ (of $24.1=1.2$ ) (taken from previously done study by Aggarwal et al. (Aggarwal et al. 2008)).

Substituting the values in the above formula:

$n=29.05$

In view of any possibility of dropouts, the sample size has been taken as 30 in each group.

The study sample was selected based on the availability of resources and comprised of 9 incisors, 5 canines, 35 premolars, and 11 molars, and among the latter were 3 third molars. The chronological age of the patients from whom the teeth were extracted was recorded. The teeth, which were extracted for orthodontic and prosthetic treatments, periodontal disease, and impactions were included in the study. Teeth with periapical pathologies, root canal treated teeth, and teeth with a history of trauma were excluded from the study.

\section{Preparation of ground sections}

The extracted teeth were preserved in 10\% buffered formalin. Formalin fixed teeth were rinsed in water for several hours. Teeth were then treated with sodium hypochlorite and hydrogen peroxide to remove the organic debris and stains. Longitudinal sections of teeth were prepared using low-speed micromotor and diamond disc. The sections were then ground using Arkansas stone. The sections were then mounted using DPX.

\section{Microscopic analysis}

These sections were examined under a phase contrast microscope at a magnification of $\times 10$, using an Olympus research microscope (BX53). On microscopic examination, the cementum showed alternately arranged dark band and light band. One dark band along with a light band following it was considered as one annulation.

The middle portion of the root was selected for counting the annulations (Tyagi and Tyagi 2014). The apical part of cementum was excluded because of the increase in thickness and cellularity of cementum in this region (Avadhani et al. 2009).

The measurements were made for the total width of the cementum and the width between two adjacent 
incremental lines (Figs. 1 and 2). The width of cementum was taken from the surface of cementum to the dentinocemental junction (DCJ) and the width between two incremental lines was taken between two adjacent lines which were easily recognizable and seemed to run approximately parallel to each other (Figs. 3 and 4).

The area selected for counting was photographed under $\times 10$ magnification, using a digital camera. The images were then transferred from the microscope to a computer, and counting was done with the help of image analyzer software (ScopeImage 9.0). To reduce interobserver variability, the counting of cemental lines was done by three observers. The mean value of the three observations was used for statistical evaluation.

\section{Estimation of age}

The number of incremental lines in the total cementum width was calculated by the formula:

Number of incremental lines $(n)=X / Y$

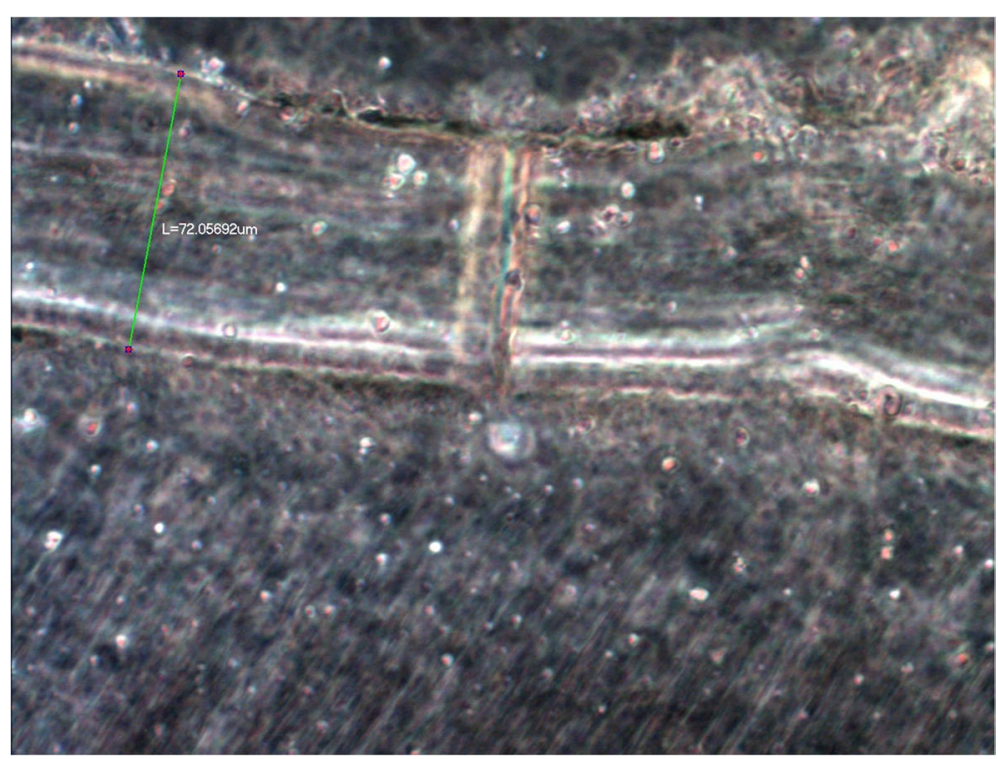

Fig. 1 Photomicrograph of normal tooth showing measurement of the total width of cementum (ground section $\times 10$ )

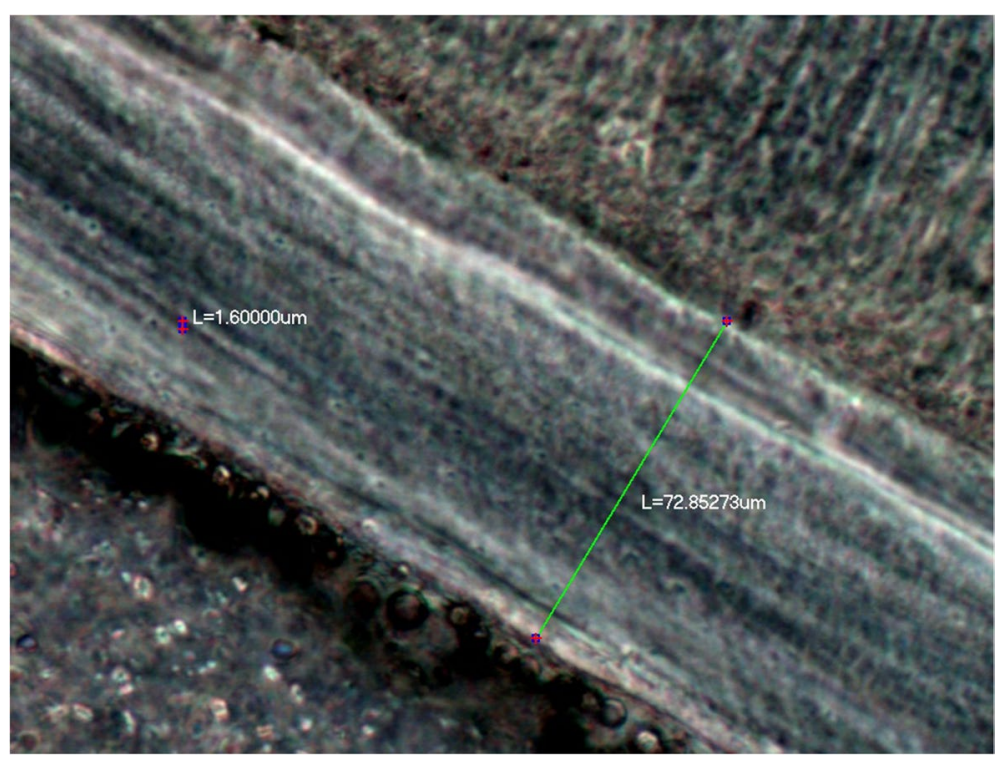

Fig. 2 Photomicrograph of periodontally diseased tooth showing measurement of the total width of cementum (ground section $\times 10$ ) 


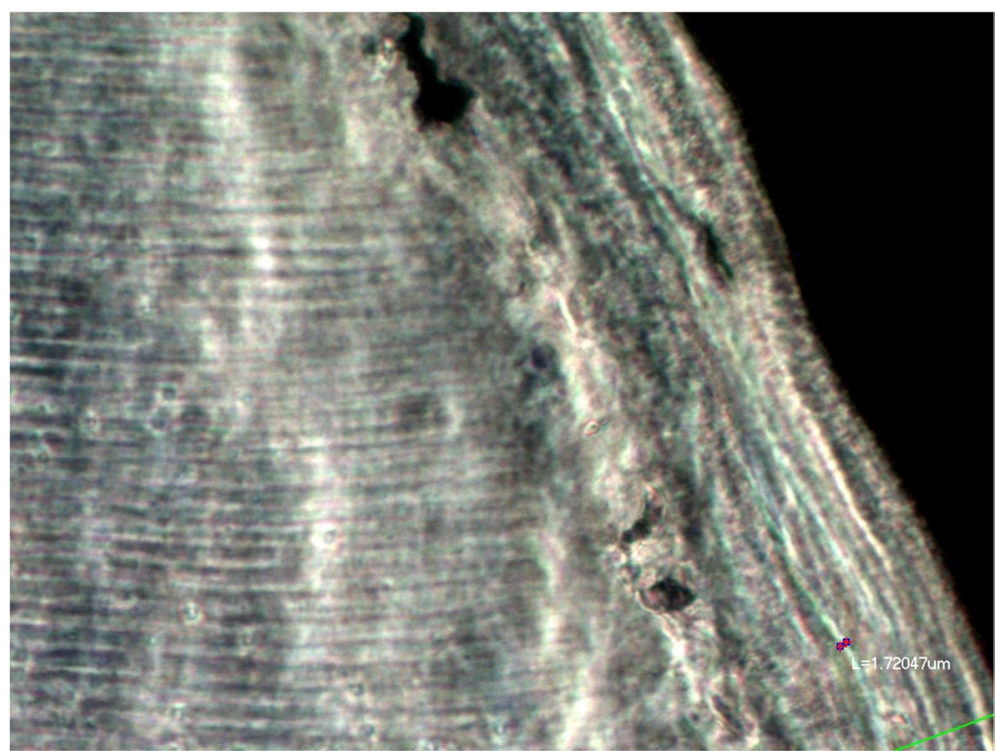

Fig. 3 Photomicrograph of normal tooth showing measurement of the width between two incremental lines of cementum (ground section $\times 10$ )

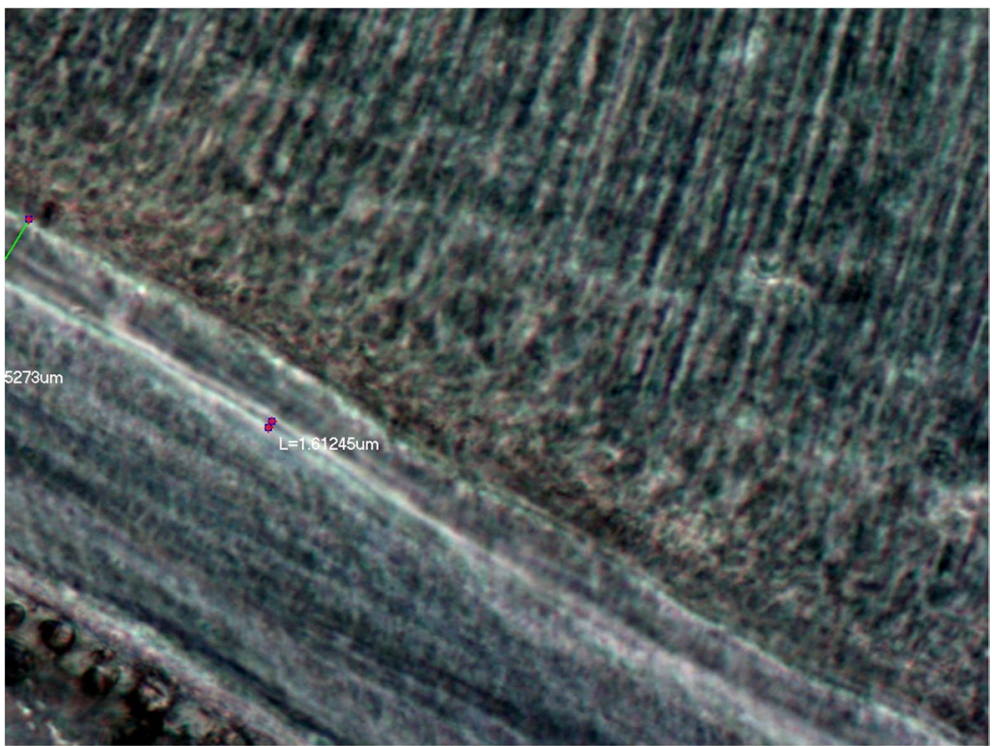

Fig. 4 Photomicrograph of periodontally diseased tooth showing measurement of the width between two incremental lines of cementum (ground section $\times 10$ )

where $X$ is the total width of cementum (from DCJ to cementum surface) and $Y$ is the width of cementum between the two incremental lines.

The chronological age of the individual was obtained by adding the average age of eruption in years for each tooth to the counted number of incremental lines (Aggarwal et al. 2008).
Estimated age $(E)=$ number of incremental lines $(n)$ + eruption age of tooth $(t)$

\section{Statistical analysis}

The data obtained was subjected to statistical analysis. Data was analyzed using Statistical Package for the Social Sciences (SPSS) Ver 23. 
1. Descriptive, Student's paired $t$ test was done for intragroup comparison of actual age and estimated age.

2. Regression analysis was done for the reliability of the procedure of age estimation in normal and periodontally diseased teeth.

\section{Results}

Dark and light incremental bands of cementum were observed in all the longitudinally sectioned specimens. Cemental annulations in longitudinal sections of sixty teeth, respectively, were counted and analyzed for their correlation with the actual age of the person using a phase contrast microscope. The measurements of cemental annulations, calculated, and the actual chronological age of individuals were tabulated for sections of normal teeth and sections of periodontally diseased teeth.

The mean and SD of actual age and estimated age in both groups are compiled in Table 1. There are statistically significant differences present in the mean values of actual age and estimated age in both the groups $(p=0.002),(-)$ value indicates that actual age is less than the predicted age (Fig. 5).

Table 2 is a consolidated regression analysis test output. For normal teeth, the reliability value of 0.92 which indicates the equation for age estimation is $92 \%$ accurate and the standard error of the estimate is 1.68 which indicates that out of 100 entries there is a chance of error in 2 individuals $(p<0.01)$ (Fig. 6). For periodontally diseased teeth, the reliability value of 0.96 which indicates the equation for age estimation is $96 \%$ accurate and the standard error of the estimate is 1.70 which indicates that out of 100 entries there is a chance of error in 2 individuals $(p<0.01)$ (Fig. 7). The scatter plot revealed only minor deviations from the normal distribution and allowed regression analysis.

Based on the regression analysis the following regression equations were derived to enable age estimation of teeth by TCA method using phase contrast microscopy:

Equation for age estimation in normal teeth $(Y)=0.79$ $+0.94 \times$ estimated age $(X)$

Equation for age estimation in periodontally diseased teeth $(Y)=1.54+0.99 \times$ estimated age $(X)$

\section{Discussion}

Age estimation is a domain of the forensic sciences which forms an important part of every identification process, especially when information relating to the deceased is unavailable. Teeth are considered to be a source of abundant data in the process of somatic development and the vicinity in which they are formed. The periodic incremental features present in teeth provide information on the developmental rate and can be used to assess the developmental age of a tooth (Smith et al. 2006).

Cementum is one such specialized calcified structure of teeth that covers the entire surface of the root. Cementum is deposited in layers during and after the eruption of the tooth leading to the formation of two types of layers with different optical properties. Histologically, these layers are visible as alternate light and dark lines or bands (Liberman 1994; Cool et al. 2002).

Each pair of these alternate bands accounts for one incremental deposit. The number of incremental deposits when added to the chronological year of eruption of the respective tooth gives the histologic age of the individual under study (Kagerer and Grupe 2001). Cementum comprises of a biological evidence that can be used to estimate the age of the individual (Zander and Hurzeler 1958). Many researchers have suggested the use of cementum of teeth for the determination of human chronological age (Avadhani et al. 2009).

Cementum annulations have been studied in previous literature extensively in animals and humans (Stott et al. 1982). Several authors have studied TCA for age estimation and reported varied findings ranging from failure in applying the technique to humans, to a significantly low margin of error in age estimations for this technique (Alghonamy et al. 2015). So, the present study was designed to evaluate human age using the TCA method.

In the current study, a sample of sixty extracted teeth was included from patients with an age range between 20 and 50 years old since by the age of 20 years growth and dental development were completed as confirmed by Someda et al. (Someda et al. 2009).

The method of tooth sectioning is also an important consideration (Mallar et al. 2015). Longitudinal sections allow examining the whole root surface such

Table 1 Comparison of mean values of actual age and predicted age in both groups

\begin{tabular}{|c|c|c|c|c|c|c|c|c|c|}
\hline \multirow[t]{2}{*}{ Group } & \multirow[t]{2}{*}{$N$} & \multicolumn{2}{|c|}{ Actual age } & \multicolumn{2}{|c|}{ Estimated age } & \multicolumn{4}{|c|}{ Mean difference in age } \\
\hline & & Mean & SD & Mean & SD & Mean & SD & $t$ value & $p$ value \\
\hline Normal teeth & 30 & 27.833 & 5.9659 & 28.903 & 6.1250 & -1.07 & 1.7 & -3.442 & $0.002^{* *}$ \\
\hline $\begin{array}{l}\text { Periodontally compro- } \\
\text { mised teeth }\end{array}$ & 30 & 39.367 & 8.4261 & 40.393 & 8.4818 & -1.02 & 1.67 & -3.354 & $0.002^{* *}$ \\
\hline
\end{tabular}

** Statistically highly significant $(p<0.01)$ 


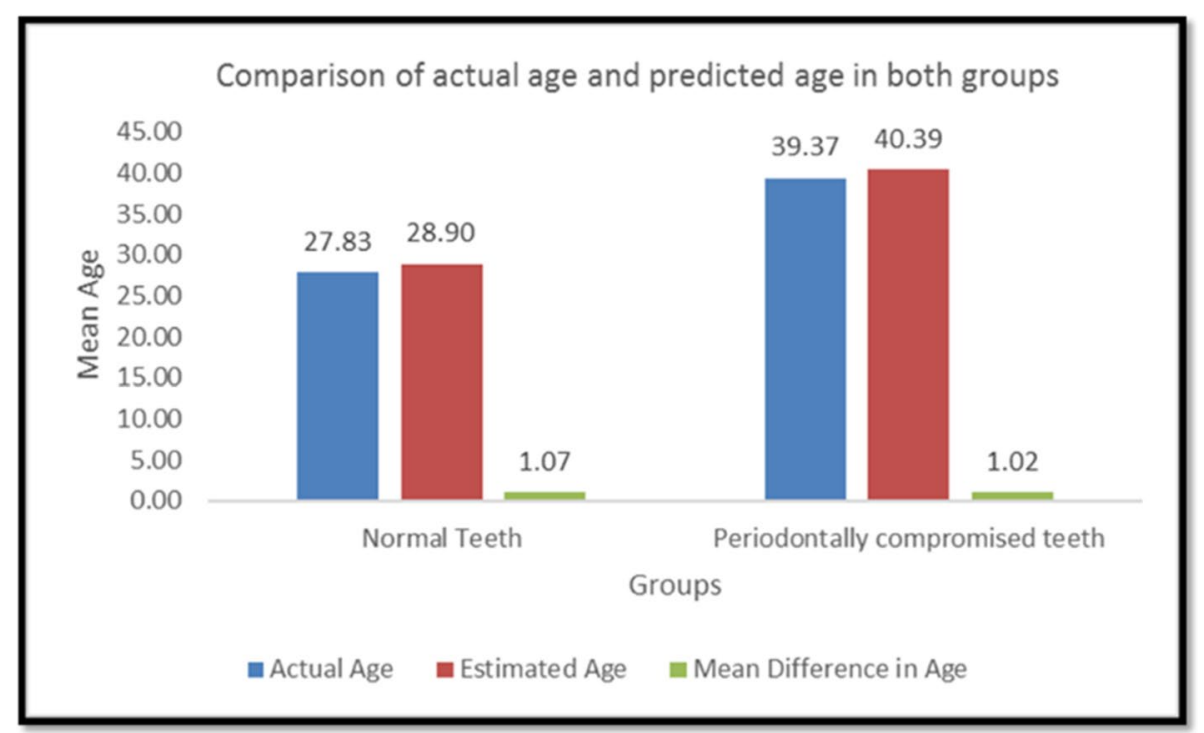

Fig. 5 Graph showing the comparison of actual age and predicted age in both groups

as advocated by Klevezal and Kleinenberg (Klevezal and Kleinenberg 1967). Stott et al. (Mallar et al. 2015), Avadhani et al. (Avadhani et al. 2009), and Mallar et al. (Mallar et al. 2015) compared longitudinal sections with cross-sections for age estimation and found that longitudinal sections were better than cross-sections for estimating age (Mallar et al. 2015). Klevezal and Kleinenberg (Klevezal and Kleinenberg 1967) and Maat et al. (Maat et al. 2006) preferred cross-sections and recommended to cut the sections perpendicular to the exterior of the root not perpendicular to the root axis. So, in the present study, longitudinal sections have been used to evaluate cemental annulations.

Various authors have compared the feasibility of counting cemental annulations using different microscopes. Pundir et al. estimated age based on the TCA method using bright field, polarizing, and phase contrast microscopy and suggested that the incremental lines are best viewed through phase contrast microscopy (Sanderson 2000). Similar findings were suggested in other studies conducted by Bhondey et al. (Pundir et al. 2009), Gowda et al. (Gowda Charan et al. 2014), and Kaur et al. (Bhondey et al. 2015), who observed that phase contrast microscopy was better than light microscopy for evaluating the cemental lines. The clarity of TCA by phase contrast microscope was explained by Sanderson who discussed how phase contrast microscope can properly distinguish between two types of layers with different optical properties. He depicted that a phase contrast microscope is suitable for viewing colorless and transparent specimens (as cementum) (Kaur et al. 2015). The present work illustrated that the use of phase contrast microscopy served as a good observatory for assessing cementum annulations.

Manual counting of cemental lines is time-consuming and is potentially subjective. The use of an image analyzer has got an added advantage of enhancing the view for measuring the cemental lines. In the present study, phase contrast microscopy in conjunction with an image analyzer was used to enhance the cemental annulations, thereby reducing the margin of error of using a simpler microscopic method.

The results of our study are in consensus with Charles et al. (Charles et al. 1986), Condon et al. (Condon et al.

Table 2 Regression analysis for validation of the estimated age

\begin{tabular}{|c|c|c|c|c|c|c|c|c|c|c|c|}
\hline Group & Variables & $B$ & Standard error & $t$ Stat & $P$ value & Lower $95 \%$ & Upper 95\% & $R$ square & Std error & $F$ value & Sig \\
\hline \multirow[t]{2}{*}{ Group 1} & Intercept & 0.79 & 1.51 & 0.52 & 0.61 & -2.30 & 3.88 & 0.922 & 1.685 & 335.12 & $<0.001^{* *}$ \\
\hline & Actual age & 0.94 & 0.05 & 18.31 & 0.00 & 0.83 & 1.04 & & & & \\
\hline \multirow[t]{2}{*}{ Group 2} & Intercept & 1.54 & 1.51 & 1.02 & 0.31 & -1.55 & 4.64 & 0.961 & 1.702 & 691.91 & $<0.001^{* *}$ \\
\hline & actual age & 0.99 & 0.04 & 26.30 & 0.00 & 0.91 & 1.06 & & & & \\
\hline
\end{tabular}

** Statistically highly significant $(p<0.01)$ 


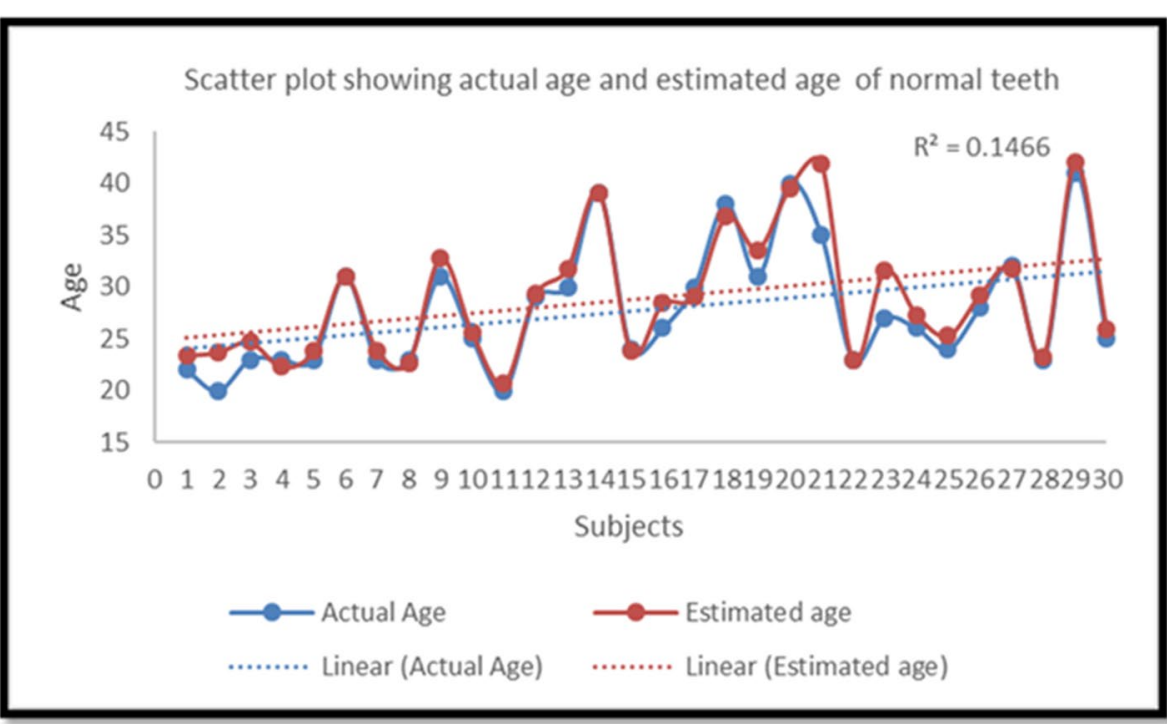

Fig. 6 Scatter plot showing actual age and estimated age of normal teeth

1986), Maat et al. (Maat et al. 2006), and Witwer Backofen et al. (Wittwer et al. 2004), who reported a wellcorrelated connection between cementum layering and chronological age in their studies with a significant $p$ value of $<0.05$. Gupta et al. (Gupta et al. 2014) also reported a strong positive correlation between estimated age from cemental lines and actual age. However, our results contradict the studies done by Lipsinic et al. (Lipsinic et al. 1986), Lucas and Loh, and Miller et al., who did not reveal a relationship between chronological age and count of tooth cementum annulations in their studies (Kaur et al. 2015).
In the current research, we assessed the TCA method for age estimation in normal teeth and periodontally compromised teeth. Wittwer Backofen et al. (Wittwer et al. 2004) used the computer software for counting the cemental annulations and found that the variation between the actual and estimated age was found to be in the range of 2-3 years. Aggarwal et al. (Aggarwal et al. 2008), in their study, found a mean error of 1-2 years. In our study, the variation between the actual and estimated age was found to be 1 year in both normal and periodontally compromised teeth. The calculated probability is 0.002 for both the groups which is statistically highly significant $\left(p^{<} 0.01\right)$.

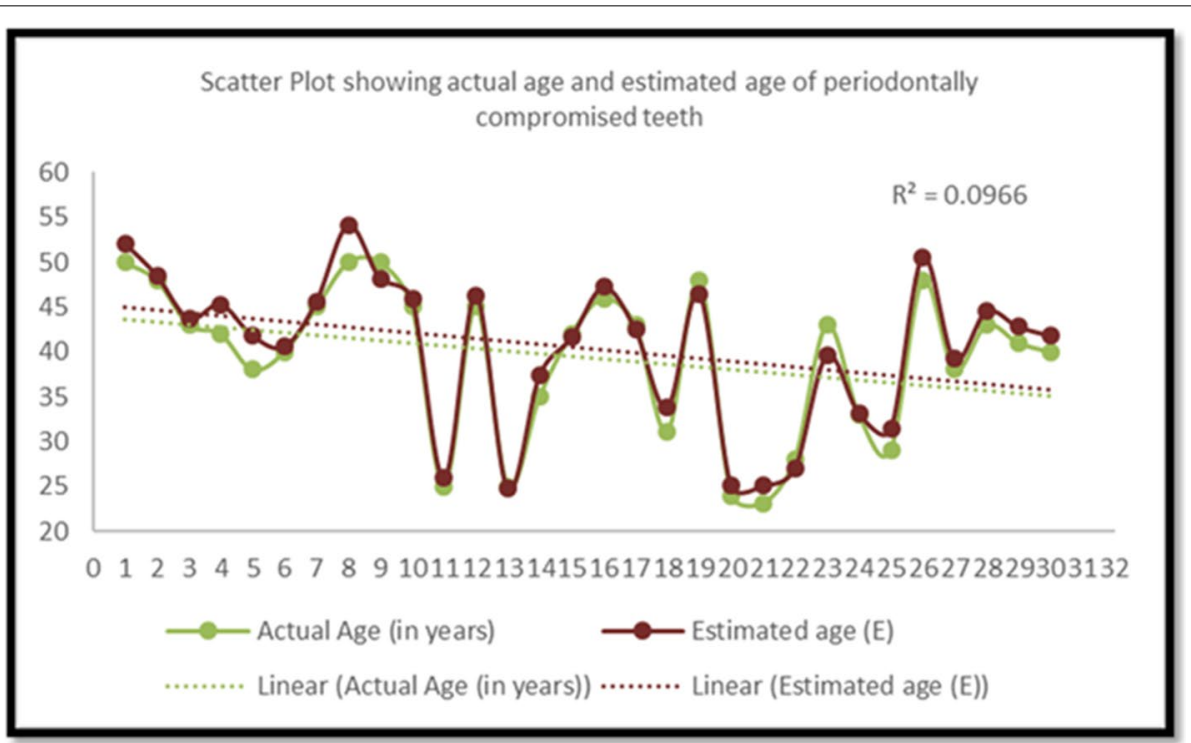

Fig. 7 Scatter plot showing actual age and estimated age of periodontally diseased teeth 
The variability in the age of eruption of a certain tooth type and also the incremental line count will always lead to an age determination within a certain range, but in our study, we considered the mean eruption age rather than the eruption age range. If the age range of eruption of the tooth was considered, it would correspond to the variation range in calculated age.

The statistics also revealed the effect of periodontal health on age estimates. The results of the present study showed that TCA is applicable to periodontally sound teeth as well as in periodontally diseased teeth. It is observed that normal teeth showed a reliability value of $92 \%$ and periodontally compromised teeth showed $96 \%$, respectively. Our study is found to be in accordance with Wittwer Backofen (Wittwer et al. 2004), Aggarwal (Aggarwal et al. 2008), and Tyagi (Tyagi and Tyagi 2014) who concluded that the cemental annulation count did not vary in the presence of periodontal disease, but our findings contradicted the results of Dias (Dias et al. 2010), who suggested that a correlation exists between incremental cemental lines and actual age; however, this correlation decreased if individuals have periodontal problems. Kvaal and Solheim (Wittwer et al. 2004) found that teeth extracted because of periodontal disease showed a weaker correlation with age than did the sound teeth. Kagerer and Grupe (Kagerer and Grupe 2001) depicted that periodontally affected teeth with sufficient nutritional support of their roots showed a minimal deviation of histological age from the known age.

In our study, we assessed a lower mean age (age range 20-50 years), as literature recommended an age-limited applicability of the TCA method for age estimation (Wittwer et al. 2004). According to studies conducted by Kvaal et al., Aggarwal et al., and Gupta et al., they found that in lower age groups the correlation coefficients between chronological tooth age and incremental lines were stronger than in the higher age groups (Aggarwal et al. 2008; Gupta et al. 2014; Kvaal and Solheim 1995). The accuracy of the tooth cemental annulation method decreased with increasing age. Usually, this was interpreted as a metabolic disorder of higher age with the influence of periodontal regression, dental caries, or other individual characters cumulating over age (Kerr and Arbor 1961). Previous studies indicated that predicted age counts for those over 55 years of age showed greater divergence from the actual age (Wittwer et al. 2004). Similar to the previous studies, we have also found a stronger correlation in a lower age group.

Our study sample included 3 samples of third molar teeth, 2 in the normal teeth group and 1 in the periodontally involved group. Deviation of calculated age from actual age was observed in these teeth. Third molars are teeth with the highest variability concerning anatomy, agenesis, and age of eruption and therefore its significance as a developmental marker has been questioned. Age estimation by means of third molars is limited due to its biological variance (Thorson and Hagg 1991).

To reduce interobserver variability, the mean value of three observations was taken; however, calculating the intraclass correlation coefficient to measure the reliability of these three measurements would be more reliable.

In the current research, we also observed that there was no substantial influence of periodontal health on the estimated age. This provides a strong support for the application of the TCA method in archeological skeletal samples in which most individuals suffered from extreme dental disease.

According to our study, we found that the tooth cementum annulation technique is a reliable method for age estimation when used with special microscopic methods such as phase contrast microscopy and digital image enhancement procedures.

\section{Conclusions}

Teeth are particularly useful in age estimation as they display a number of observable age-related variables and they tend to remain intact under circumstances which might alter or obliterate the rest of the skeleton. The histological assessment of countable cemental annulations of teeth using phase contrast microscope and digital enhancement for estimation of age narrows down the error rate to just over 1 year making this method more reliable in both sound and periodontally diseased teeth. This technique may be extremely valuable in forensic medicine, forensic dentistry, and anthropology. Further studies are needed to determine the availability of TCA for individuals older than 50 years. A much larger sample size would shed more light on evaluating the impact of periodontal disease on the estimated age.

\section{Abbreviations}

TCA: Tooth cemental annulations; DCJ: Dentinocemental junction.

\section{Supplementary Information}

The online version contains supplementary material available at https://doi. org/10.1186/s41935-021-00254-2.

Additional file 1.

Acknowledgements

Not applicable.

Authors' contributions

AS conducted the study by preparing and analyzing the histological sections of teeth, interpreted the data, and was a major contributor in writing the manuscript. HZ designed the study, analyzed and interpreted the data, and 
reviewed the manuscript. PJ reviewed the literature, analyzed and interpreted the data, and contributed in writing the manuscript. DH designed the study and analyzed and interpreted the data. S interpreted the data and revised the manuscript. All authors have read and approved the final manuscript and have approved the submission of the revised manuscript.

\section{Funding}

Not applicable

\section{Availability of data and materials}

All data analyzed during this study are included as supplementary information file.

\section{Declarations}

\section{Ethics approval and consent to participate}

Ethical approval was obtained from the Institutional Ethical Review Board. Reference number: IERB/2015-16/16. The ethical certificate is submitted as supplementary information file. A written consent was obtained from the patients whose extracted teeth were included in the study.

\section{Consent for publication}

Not applicable.

\section{Competing interests}

The authors declare that they have no competing interests.

\section{Author details}

'Department of Oral Pathology and Microbiology, Al Badar Dental College and Hospital, Kalaburagi, Karnataka 585102, India. ${ }^{2}$ Department of Oral Pathology, RR Dental College and Hospital, Udaipur, India. ${ }^{3}$ Integro Hospital, Hyderabad, Telangana, India.

Received: 16 January 2021 Accepted: 1 November 2021

Published online: 24 November 2021

\section{References}

Aggarwal P, Saxena S, Bansal P (2008) Incremental lines in root cementum of human teeth: An approach to their role in age estimation using polarizing microscopy. Indian J Dent Res 19:326-330

Alghonamy WY, Gaballah OM, Labah DA (2015) Age estimation in adult human sound and periodontally affected teeth using tooth cementum annulations. Tanta Dental J 12(4):277-285

Avadhani A, Tupkari JV, Khambaty A, Sardar M (2009) Cementum annulations and age determination. J Forensic Dent Sci 1:73-76

Bhondey A, Thakur M, Palve D, Dhengar YS, Bhagwatkar T, Chaturvedi S (2015) Age revealing annulations: Application for estimation of age in central India population. Ann Dent Special 3(4):96-99

Charles DK, Condon K, Cheverud J, Buikstra J (1986) Cementum annulation and age determination in homo sapiens. I - Tooth Variability and Observer Error Am J Phys Anthropol 71:311-320

Condon K, Charles DK, Cheverud J, Buikstra J (1986) Cementum annulation and age determination in homo sapiens. II- Estimates and Accuracy. Am J Phys Anthropol 71:321-330

Cool SM, Forwood MR, Campbell P, Bennett MB (2002) Comparisons between bone and cementum compositions and the possible basis for their layered appearances. Bone 30:386-392

Dias PEM, Beaini TL, Melani RFH (2010) Age estimation from dental cementum incremental lines and periodontal disease. J Forensic Odontostomato 28(1):13-21

Gowda Charan BK, Reddy SP, Kokila G, Pradeep L (2014) Cemental annulation and phase contrast microscope: Tool for age estimation. J SIMLA 6:9-13

Gupta P, Kaur H, Shankari GSM, Jawanda MK, Sahi N (2014) Human age estimation from tooth cementum and dentin. J Clin Diagn Res 8(4):ZC07-ZC10

Irish JD, Scott GR (2016) A companion to dental anthropology, 1st edn. Wiley Blackwell, UK
Kagerer P, Grupe G (2001) Age-at-death diagnosis and determination of life history parameters by incremental lines in human dental cementum as an identification aid. Forensic Sci Int 118:75-82

Kaur P, Astekar M, Singh J, Arora KS, Bhalla G (2015) Estimation of age based on tooth cementum annulations: A comparative study using light, polarized, and phase contrast microscopy. J Forensic Dent Sci 7:215-221

Kerr DA, Arbor A (1961) The cementum: its role in periodontal health and disease. J Periodontol 32(3):183-189

Klevezal GA, Kleinenberg SE (1967) Age determination of mammals from annual layers in teeth and bones. US Department of Commerce, Spring field

Kvaal SI, Solheim T (1995) Incremental lines in human dental cementutn in relation to age. Eur J Oral Sci 103:225-230

Liberman DE (1994) The biological basis for seasonal increments in dental cementum and their application to archeological research. J Archeol Sci 21:525-539

Lipsinic FF, Paunovich E, Houston GD, Robison SF (1986) Correlation of age and incremental lines in the cementum of human teeth. J Forensic Sci 31:982-989

Maat G, Gerresten R, Aarents M (2006) Improving the visibility of tooth cementum annulations by adjustment of cutting angle of microscopic sections. Forensic Sci Int 1595:595-599

Mallar KB, Girish HC, Murgod S, Kumar Yathindra BN (2015) Age estimation using annulations in root cementum of human teeth: a comparison between longitudinal and cross sections. J Oral Maxillofacial Pathol 19:396-404

Meinl A, Huber CD, Tangl S, Gruber GM, Teschler-Nicola M, Watzek G (2008) Comparision of three dental methods for the estimation of age of death. Forensic Sci Int 178:96-105

Pundir S, Saxena S, Aggarwal P (2009) Estimation of age based on tooth cementum annulations using different microscopic methods. J Forensic Dent Sci 1:82-87

Sanderson J (2000) The theory of contrast control in the microscope. Quekett J Microsc 38:617-627

Schemeling A, Dettmeyer R, Rudolf E, Vieth N, Geserick G (2016) Forensic age estimation- methods, certainity and the law. Dtsch Arztebl Int 113:44-50

Smith TM, Reid DJ, Sirianni JE (2006) The accuracy of histological assessments of dental development and age at death. J Anat 208:125-138

Someda H, Saka H, Matsunaga A, Ide Y, Nakahara K, Hirata S et al (2009) Age estimation based on three-dimensional measurement of mandibular central incisors in Japanese. Forensic Sci Int 185:110-114

Stott GG, Sis RF, Levy BM (1982) Cemental annulation as an age criterion in forensic dentistry. J Dent Res 61(6):814-817

Thorson J, Hagg U (1991) The accuracy and precision of third molars as an indicator of chronological age. Swed Dent J 15(1):15-21

Tyagi N, Tyagi R (2014) Dental age estimation using cemental annulations: Lines to ponder. Am J Res Commun 2:127-137

Wittwer BU, Gampe J, Vaupel JW (2004) Tooth cementum annulation for age estimation: results from a large known-age validation study. Am J Phys Anthropol 123:119-129

Zander HA, Hurzeler B (1958) Continuous cementum apposition. J Dent Res $37: 1035-1044$

\section{Publisher's Note}

Springer Nature remains neutral with regard to jurisdictional claims in published maps and institutional affiliations. 